\title{
Impact of Mechanical Ventilation Methods on the Life Perception of Subjects With Duchenne Muscular Dystrophy: French Cross-Sectional Survey
}

\author{
Ghilas Boussaïd, Caroline Stalens, Christian Devaux, Sandrine Segovia-Kueny, Frédéric Lofaso, \\ and Christian Reveillere
}

\begin{abstract}
BACKGROUND: The life expectancy of individuals with Duchenne muscular dystrophy has improved considerably with the use of mechanical ventilation to manage respiratory insufficiency. The choice between continuous noninvasive ventilation (NIV) and invasive ventilation is guided both by local logistical considerations and by clinical considerations, but the choice depends largely on patient preference. It is important to know the effects of ventilatory dependence and the method used (ie, continuous NIV or invasive ventilation) on subjects' quality of life. METHODS: This was a cross-sectional prospective survey of 192 subjects with Duchenne muscular dystrophy using mechanical ventilation in France. Subjects were grouped and compared according to dependence on mechanical ventilation and the ventilation methods used. RESULTS: Regardless of the mechanical ventilation method, subjects with gastrostomy tubes reported more frequent emergency consultations for digestive problems $(22.5 \%$ vs $4.6 \%, P=$ .001). Subjects with invasive ventilation reported more insomnia than those with continuous NIV $(23.8 \%$ vs $8.5 \%, P=.04)$. The latter reported more ineffective cough than the invasive ventilation group $(72.3 \%$ vs $49.2 \%, P=.02)$. Overall, the subjects in our sample were satisfied with their medical care, regardless of dependence level or ventilation type. More specifically, $86.1 \%$ of subjects with intermittent NIV and $83.6 \%$ of ventilator-dependent subjects were satisfied. CONCLUSIONS: Continuous and invasive mechanical ventilation did not affect the perception of quality of life for our subjects with Duchenne muscular dystrophy, apart from more insomnia, which can be explained by the fact that they required frequent repositioning in bed. Different pressure-relief mattresses should be tested and compared to prevent the development of pressure ulcers, which may improve the sleep patterns of these patients. Key words: Duchenne muscular dystrophy; continuous noninvasive ventilation; invasive ventilation; quality of life; French cross-sectional survey. [Respir Care 2020;65(11):1712-1720. (C) 2020 Daedalus Enterprises]
\end{abstract}

\section{Introduction}

Duchenne muscular dystrophy mainly affects males, with an incidence of $\sim 0.03 \%$ of males at birth. ${ }^{1,2}$ Life expectancy has considerably improved with the use of mechanical ventilation to manage respiratory insufficiency. ${ }^{3}$

All authors are affiliated with the Direction des Actions Médicales, AFM-Téléthon, Evry, France. Drs Boussaïd and Lofaso are affiliated with the Université Paris-Saclay, Versailles, France. Dr Lofaso is affiliated with the Service d'Explorations Fonctionnelles Respiratoires, Hôpital Raymond Poincaré, Garches, France. Dr Reveillere is affiliated with the Qualité de vie et santé psychologique, Université de Tours, Tours, France.
Generally, mechanical ventilation with a noninvasive interface is intermittent and used at night to treat sleep-related breathing disorders or hypoventilation, which occur mainly during rapid eye movement sleep. ${ }^{4-6}$ Several studies have reported that the quality of life of subjects with Duchenne muscular dystrophy with home ventilation is comparable or

\footnotetext{
This work was supported in part by AFM Téléthon. The authors have no disclosed no conflicts of interest.

Correspondence: Ghilas Boussaïd PT PhD, AFM-Téléthon, 1 Rue de l’Internationale, 91000 Évry, France. E-mail: boussaid.gh@gmail.com.
}

DOI: $10.4187 /$ respcare. 07131 
better than that of other subject groups,${ }^{7,8}$ better even than that observed in the general population. ${ }^{9,10}$ Improvements in sleep architecture during noninvasive ventilation (NIV) have also been documented and may contribute to the better well-being of these patients. ${ }^{11}$

Progression of the muscular dysfunction results in the occurrence of diurnal symptoms, notably hypercapnia. In these cases, NIV must be extended beyond the night to include a substantial period of daytime ventilator support, gradually becoming continuous to relieve symptoms and to maintain acceptable blood gas levels.

In the past, when individuals became dependent on mechanical ventilation, tracheostomy was almost invariably proposed. ${ }^{12}$ With the improvement of respiratory assistance technology, including cough assist devices, continuous NIV, which may require the use of a mouthpiece during the day, provides an alternative to tracheostomy and is now offered in the first instance. Toussaint et $\mathrm{al}^{13}$ reported improved respiratory symptom scores and life expectancy of subjects with Duchenne muscular dystrophy with daytime mouthpiece ventilation associated with nocturnal nasal ventilation. This suggests that invasive ventilation should be avoided or delayed, giving preference to continuous NIV. ${ }^{5}$ Currently, the decision to perform a tracheostomy is guided by local logistical considerations and by clinical concerns such as bulbar dysfunction and the need for tracheal aspiration, despite systematic cough assistance, and also by subject preference. ${ }^{14}{ }^{17}$ Studies have reported inconsistent results concerning the survival rate of people with Duchenne muscular dystrophy, depending on the methods used to treat ventilator dependence (noninvasive or invasive). ${ }^{15,18-21}$

Finally, because the choice between continuous NIV and invasive ventilation depends largely on subject preference, it is important to know the effects of ventilator dependence and the method used (ie, continuous NIV vs invasive ventilation) on patients' quality of life. A seminal study demonstrated that people with neuromuscular disorders who had experienced both techniques tended to prefer noninvasive methods to tracheostomy. ${ }^{22}$ However, many of them were tracheostomized under acute conditions and had no subsequent need of it. Moreover, the subjects in that study were heterogeneous (ie, not exclusively neuromuscular diseases or Duchenne muscular dystrophy). Furthermore, advances in technology over the last 10 years have improved the management of tracheostomized subjects, particularly regarding speech and swallowing. ${ }^{23-25}$

The main aim of this study was to assess the perceived benefits and disadvantages of different methods of ventilation (NIV vs invasive ventilation) and level of dependence (nocturnal vs dependent). To avoid any impact of medical opinion on the subjects' responses, a questionnaire was developed and validated by the French Muscular Dystrophy Association (AFM-Téléthon) and was sent directly to subjects.

\section{QUICK LOOK}

\section{Current knowledge}

The decision to perform tracheostomy is guided by logistical as well as clinical considerations such as bulbar dysfunction, the need for tracheal aspiration despite systematic cough assistance, and patient preference. Technological advances have improved the management of tracheostomized patients, particularly regarding phonation and swallowing, through specific ventilator modalities. Because the choice of mechanical ventilation method depends largely on patient preference, it is important to know the effects of the method of ventilation and ventilator dependence on quality of life.

\section{What this paper contributes to our knowledge}

Invasive mechanical ventilation did not impact the life perception of subjects with Duchenne muscular dystrophy apart from more insomnia, which can be explained by the need to change their position in bed several times during the night. Different anti-pressure mattresses should be tested and compared to prevent pressure ulcers and hence improve the sleep of these individuals.

\section{Methods}

\section{Study Design}

We conducted a cross-sectional prospective survey of patients with dystrophinopathies, registered with the family services department of AFM-Téléthon in France between November 2013 and January 2014. Data were collected by the health department of OpinionWay, who provided methodological and logistical support. The study protocol was approved by an association of professionals from AFM-Téléthon and doctors who specialized in the diagnosis and management of these diseases, after ensuring that subject data remained anonymous. The project was funded by AFM-Téléthon.

A steering committee composed of doctors, epidemiologists, and physiotherapists designed and organized the survey. Two data collection methods were used to maximize the number of respondents: a paper questionnaire sent to 2,083 people affected by these diseases, and an online platform was created to collect data electronically.

Males with Duchenne muscular dystrophy using mechanical ventilation (ie, noninvasive or invasive interface) were eligible for this study. Data, collected via a 


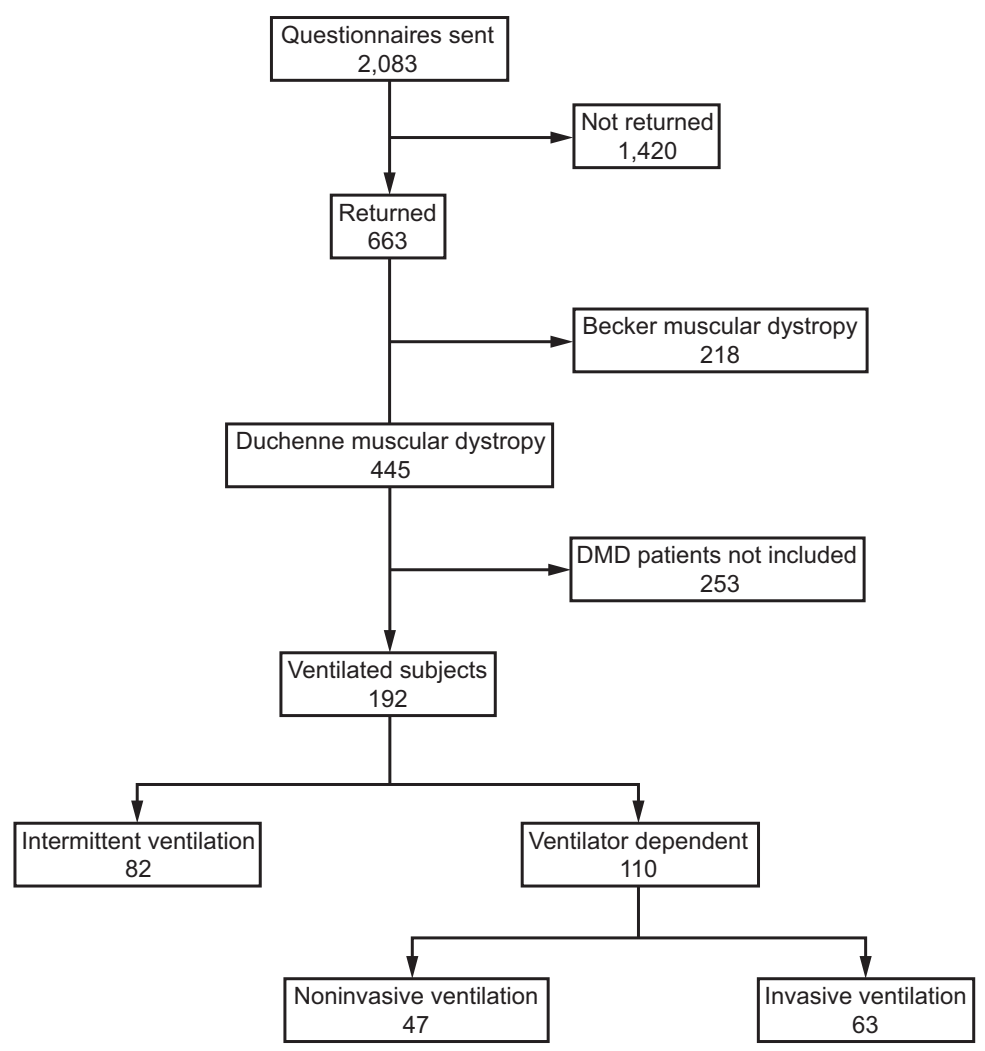

Fig. 1. Flow chart of subjects with dystrophinopathy registered in the family services department of AFM-Téléthon, France, between November 2013 and January 2014. DMD = Duchenne muscular dystrophy.

questionnaire about daily activities, included age, sociodemographic factors, medical and paramedical care, and perception of quality of life. The questionnaire was completed by the subject (or by the subject's family) and checked by a health-social professional (eg, physical therapist, occupational therapist, education specialist).

\section{Statistical Analysis}

Descriptive statistics are presented as figures and percentages, or means and standard deviations, with skewed continuous data summarized as medians and interquartile ranges. Subjects were grouped according to dependence on mechanical ventilation (ie, those on intermittent or continuous ventilation) and to the method used (ie, noninvasive ventilation [NIV] or invasive ventilation), and the groups were compared. A Student $t$ test (equal variance) or Welche-Satterthwaite $t$ test (unequal variance) was used to analyze quantitative variables; a MantelHaenszel chi square test was used to analyze qualitative variables; and a Fisher exact test was used when the sample sizes were small (ie, $<5$ ). Statistical significance was set at 0.05 (2-tailed test). Analyses were performed with SAS 9.4 for Windows (SAS Institute, Cary, North Carolina).

\section{Results}

Between 2013 and 2014, 2,083 patients with dystrophinopathy were registered with the family services department of AFM-Téléthon in France. Of these, 663 (32\%) answered the questionnaire, including 445 (67\%) with Duchenne muscular dystrophy and 218 (33\%) with Becker muscular dystrophy. In the Duchenne muscular dystrophy group, 192 (43\%) were ventilated and were therefore included in the study (Fig. 1).

The questionnaire was completed between 2013 and 2014 by the 192 individuals with Duchenne muscular dystrophy (Table 1). There were $110(57 \%)$ subjects who were ventilator-dependent, 47 (43\%) on continuous NIV, and 63 $(57 \%)$ on invasive ventilation. Forty-eight $(25 \%)$ subjects had at least one relative with Duchenne muscular dystrophy, including 2 subjects who had both an uncle (ie, level III) and a cousin (ie, level IV) with Duchenne muscular dystrophy. In this group, 150 subjects (78\%) lived at home (24 did not answer), and more than half were unemployed (12 did not answer).

Ventilator-dependent subjects reported more swallowing difficulties $(38.2 \%$ vs $20.7 \% P=.01)$ and more aspiration problems $(40.9 \%$ vs $23.2 \%, P=.01)$ than those with intermittent NIV, with no significant difference between 


\section{Mechanical Ventilation in Duchenne Muscular Dystrophy}

Table 1. Characteristics of Ventilated Subjects With DMD

\begin{tabular}{lc}
\hline \hline Age at diagnosis, y & $4.8 \pm 2.4$ \\
Family history* & \\
Level II & $25(42)$ \\
Level III & $12(27)$ \\
Level IV & $13(27)$ \\
Age, y & $26.6 \pm 8.8$ \\
Functional status & \\
$\quad$ Age when lost ability to walk, y & $9.4 \pm 2.1$ \\
Dependence & \\
Manual wheelchair & $5(3)$ \\
Electric wheelchair & $119(62)$ \\
Standing devices wheelchair & $60(31)$ \\
Others & $8(4)$ \\
Housing solutions & \\
At home & $150(78)$ \\
Health care establishment & $5(3)$ \\
Home for handicapped adults & $13(7)$ \\
Type of activity & \\
Student & $60(31)$ \\
Working or professional training & $15(8)$ \\
Without employment & $105(57)$
\end{tabular}

Data are presented as $n(\%)$ or mean $\pm \mathrm{SD} . N=192$ subjects

* Family history is cut in function of ascendant; ie, level II = ascendant is a brother or grandfather; level III = ascendant is an uncle; level IV = ascendant is a cousin.

continuous NIV and invasive ventilation for these parameters (Table 2). Regardless of the mechanical ventilation duration or condition, subjects with gastrostomy tubes reported more swallowing difficulties than the other groups (45\% vs $27 \%, P=.031$ ) (Table 3 ). Although loss of appetite was not influenced by mechanical ventilation duration, subjects with continuous NIV reported greater loss of appetite than those with invasive ventilation $(34.0 \%$ vs $12.7 \%$, $P=.01$ ), whereas gastrostomy feeding did not affect appetite in the ventilator-dependent subjects $(P=.20)$. Gastrostomy tubes were more common among ventilatordependent subjects than among those with intermittent invasive ventilation $(30.0 \%$ vs $8.5 \%, P<.001)$, and among those with invasive ventilation than among those with continuous NIV (38.1\% vs $19.1 \%, P=.041)$. Ventilator-dependent subjects experienced more intestinal bloating than those with intermittent NIV $(60.9 \%$ vs $34.1 \%, P<.001)$, with no significant difference between continuous NIV and invasive ventilation. Regardless of the mechanical ventilation condition, subjects with gastrostomy tubes reported more frequent emergency consultations for digestive problems $(22.5 \%$ vs $4.6 \%, P=.001)$.

Ventilator-dependent subjects reported more daytime sleepiness $(12.7 \%$ vs $3.7 \%, P=.042)$ and insomnia $(17.3 \%$ vs $3.7 \%, P<.01)$ than those with intermittent NIV. Insomnia was more frequent in subjects with invasive ventilation than those with continuous NIV (23.8\% vs $8.5 \%$, $P=.04$ ) (Table 2).

Anxiety and depression concerned 76 (39.6\%) and 32 (16.7\%) subjects, respectively, although duration of mechanical ventilation and tracheostomy did not significantly affect these parameters (Table 2). In contrast, subjects with intermittent NIV reported more attention deficit than those who were ventilator-dependent $(17.1 \%$ vs $7.3 \%, P=.042)$, whereas the latter reported more pain than those with intermittent NIV (67.6\% vs $52.6 \%, P=.049)$.

Subjects with intermittent NIV reported more ineffective cough than those who were ventilator-dependent $(75.6 \%$ vs $59.1 \%, P=.02$ ) (Table 2). This problem occurred more frequently with continuous NIV than invasive ventilation (72.3\% vs $49.2 \%, P=.02)$. However, subjects with invasive ventilation reported more bronchial obstructions than those with continuous NIV $(50.8 \%$ vs $17.0 \%, P<.001)$. A total of 135 subjects $(73.8 \%)$ received respiratory therapy from a physical therapist (Table 3). The forced expiration technique, associated with endotracheal aspirations, was used more with invasive ventilation than with continuous NIV $(68.3 \%$ vs $45.3 \%, P=.01)$, whereas airway clearance devices, with or without the forced expiration technique, were used more with continuous NIV than with invasive ventilation $(20.8 \%$ vs $7.3 \%, P=.031)$. The most widely used airway clearance devices were pressure-cycled respirators and insufflators/exsufflators $(64.7 \%$ and $70.6 \%$, respectively).

Overall, the ventilated subjects in our study were satisfied with their medical care, regardless of dependence level or ventilation type; $86.1 \%$ of those with intermittent NIV and $83.6 \%$ of those who were ventilator-dependent expressed satisfaction (Table 4). Among the latter, 91.5\% with continuous NIV and $77.8 \%$ with invasive ventilation were satisfied. The results regarding perception of social life difficulty were similar regardless of the level of dependence and type of ventilation. Three dimensions were evaluated: professional life, leisure/holidays, and family life. Due to the clinical characteristics of this population, professional life did not concern $60 \%$ of the subjects. Moreover, we observed that there was no difference between the dependence level and ventilation type. The progression of the disease affected the subjects' leisure/holidays and family life (between $76.6 \%$ and $92.3 \%$ ).

In the subgroup with invasive mechanical ventilation, 29 subjects $(46.8 \%)$ were tracheostomized during an episode of acute respiratory failure, while tracheostomy had been performed for 33 subjects $(53.2 \%)$. A total of 44 subjects (70\%) received phonation management; 37 (84.1\%) used a phonation valve, 15 (34.1\%) used positive expiratory pressure to improve speech, and 7 (15.9\%) received voice rehabilitation. Finally, there was no significant link between the 
Mechanical Ventilation in Duchenne Muscular Dystrophy

Table 2. Clinical Manifestations of Subjects With DMD

\begin{tabular}{|c|c|c|c|c|c|c|}
\hline Manifestations & Intermittent NIV & Ventilator-Dependent & $P$ & Continuous NIV & Invasive Ventilation & $P$ \\
\hline Diagnosis age, y & $4.5 \pm 2.3$ & $4.9 \pm 2.6$ & NS & $5.1 \pm 2.4$ & $4.8 \pm 2.7$ & .34 \\
\hline \multicolumn{7}{|l|}{ Digestive } \\
\hline Aspiration problems & $19(23.2)$ & $45(40.9)$ & .01 & $16(34.0)$ & $29(46.0)$ & .44 \\
\hline Difficulty swallowing & $17(20.7)$ & $42(38.2)$ & .01 & $17(36.2)$ & $25(39.7)$ & .65 \\
\hline Loss of appetite & $20(24.4)$ & $24(21.8)$ & .34 & $16(34.0)$ & $8(12.7)$ & .01 \\
\hline Weight loss & $22(26.8)$ & $27(24.5)$ & .67 & $15(31.9)$ & $12(19.0)$ & .43 \\
\hline Overweight & $14(17.1)$ & $16(14.5)$ & .22 & $6(12.8)$ & $10(15.9)$ & .29 \\
\hline Intestinal bloating & $28(34.1)$ & $67(60.9)$ & $<.001$ & $24(51.1)$ & $43(68.3)$ & .65 \\
\hline Gastroesophageal reflux & $12(14.6)$ & $19(17.3)$ & .19 & $5(10.6)$ & $14(22.2)$ & .28 \\
\hline Difficulty speaking & $15(18.3)$ & $22(20.0)$ & .51 & $6(12.8)$ & $16(25.4)$ & .29 \\
\hline Pain & $41(52.6)$ & $71(67.6)$ & .049 & $32(69.6)$ & $39(66.1)$ & .67 \\
\hline \multicolumn{7}{|l|}{ Respiratory } \\
\hline Breathlessness & $20(24.4)$ & $27(24.5)$ & .38 & $10(21.3)$ & $17(27.0)$ & .54 \\
\hline Ineffective cough & $62(75.6)$ & $65(59.1)$ & .02 & $34(72.3)$ & $31(49.2)$ & .02 \\
\hline Recurrent bronchitis & $4(4.9)$ & $7(6.4)$ & .72 & $1(2.1)$ & $6(9.5)$ & .35 \\
\hline Recurrent bronchial obstructions & $26(31.7)$ & $40(36.4)$ & .37 & $8(17.0)$ & $32(50.8)$ & $<.001$ \\
\hline Sleep & $35(42.7)$ & $54(49.1)$ & .87 & $18(38.3)$ & $36(57.1)$ & .41 \\
\hline Trouble falling asleep & $19(23.2)$ & $26(23.6)$ & .47 & $7(14.9)$ & $19(3.2)$ & .39 \\
\hline Insomnia & $3(3.7)$ & $19(17.3)$ & $<.002$ & $4(8.5)$ & $15(23.8)$ & .041 \\
\hline Diurnal sleepiness & $3(3.7)$ & $14(12.7)$ & .042 & $3(6.4)$ & $11(17.5)$ & .32 \\
\hline Frequent awakenings & $26(31.7)$ & $41(37.3)$ & .17 & $13(27.7)$ & $28(44.4)$ & .67 \\
\hline Nightmare & $5(6.1)$ & $12(10.9)$ & .28 & $4(8.5)$ & $8(12.7)$ & .43 \\
\hline Others & $3(3.7)$ & $6(5.5)$ & .89 & $2(4.3)$ & $4(6.3)$ & .34 \\
\hline \multicolumn{7}{|l|}{ Neurological and mental } \\
\hline Anxiety & $26(31.7)$ & $50(45.5)$ & .36 & $19(40.4)$ & $31(49.2)$ & .59 \\
\hline Depression & $10(12.2)$ & $22(20.0)$ & .31 & $10(21.3)$ & $12(19.0)$ & .54 \\
\hline Self-esteem low & $20(24.4)$ & $23(20.9)$ & .73 & $14(29.8)$ & $9(14.3)$ & .76 \\
\hline Social isolation & $10(12.2)$ & $19(17.3)$ & .59 & $11(23.4)$ & $8(12.7)$ & .46 \\
\hline Irritability & $14(17.1)$ & $20(18.2)$ & .42 & $9(19.1)$ & $11(17.5)$ & .39 \\
\hline Memory problems & $3(3.7)$ & $4(3.6)$ & .33 & $2(4.3)$ & $2(3.2)$ & .38 \\
\hline Attention deficit & $14(17.1)$ & $8(7.3)$ & .042 & $4(8.5)$ & $4(6.3)$ & .27 \\
\hline
\end{tabular}

method of ventilation (noninvasive ventilation vs invasive ventilation) and speech difficulty (Table 2).

In our sample, 55 subjects (29\%) had been hospitalized for emergency care in the previous $2 \mathrm{y} ; 19$ (34.5\%) subjects had multiple hospitalizations (Figure 2). The most frequent causes were respiratory problems $(67.3 \%)$ and digestive problems $(29.1 \%)$. We did not observe any link between the ventilation method or dependence and reasons for emergency hospitalization.

\section{Discussion}

Although the prolongation of mechanical ventilation during the day was associated with more digestive problems, pain, insomnia, and daytime somnolence, and tracheostomy led to complications such as airway obstruction, we did not observe any influence of mechanical ventilation duration and method (invasive or noninvasive) on our Duchenne muscular dystrophy subjects' perception of their quality of life.

Although respiratory therapy was not influenced by either duration or condition of mechanical ventilation, we observed that airway clearance devices were used less frequently by tracheostomized subjects than by others (Table 3). Similarly, tracheostomized subjects reported ineffective cough less frequently than the other groups (50\% vs $75 \%$ ). These paradoxical results can probably be explained by the fact that the subjects with invasive ventilation received endotracheal suctioning/aspiration associated with the forced expiration technique and did not require considerable expiratory effort to obtain effective airway clearance. By contrast, we observed that the mechanical cough assistance technique was used mostly by subjects who were both dependent on mechanical ventilation and used a noninvasive interface. This highlights the need to improve airway clearance by increasing cough effectiveness in this vulnerable 


\section{Mechanical Ventilation in Duchenne Muscular Dystrophy}

Table 3. Therapeutic Treatments for Subjects With DMD

\begin{tabular}{|c|c|c|c|c|c|c|}
\hline Interventions & Intermittent NIV & Ventilator-Dependent & $P$ & Continuous NIV & Invasive Ventilation & $P$ \\
\hline \multicolumn{7}{|l|}{ Surgical intervention } \\
\hline Gastrostomy & $7(8.5)$ & $33(30.0)$ & $<.001$ & $9(19.1)$ & $24(38.1)$ & .04 \\
\hline Arthrodesis & $59(71.9)$ & $84(76.4)$ & .87 & $36(76.6)$ & $48(76.2)$ & .29 \\
\hline \multicolumn{7}{|l|}{ Therapy intervention } \\
\hline Respiratory therapy — yes & $53(68.8)$ & $82(77.4)$ & .74 & $36(78.3)$ & $46(76.7)$ & .52 \\
\hline \multicolumn{7}{|l|}{ Frequency of respiratory therapy } \\
\hline Daily & $4(8.2)$ & $16(19.8)$ & .56 & $8(22.9)$ & $8(17.4)$ & .76 \\
\hline 2-3 times/week & $18(36.7)$ & $34(42.0)$ & & $14(40.0)$ & $20(43.5)$ & \\
\hline$\leq 1$ times/week & $7(14.2)$ & $6(7.4)$ & & $2(5.7)$ & 4 (8.6) & \\
\hline During bronchial obstructions & $20(40.8)$ & $25(30.9)$ & & $11(31.4)$ & $14(30.4)$ & \\
\hline \multicolumn{7}{|l|}{ Type of respiratory therapy } \\
\hline Forced expiration technique & $24(45.3)$ & $56(68.3)$ & .01 & $22(61.1)$ & $34(73.9)$ & .32 \\
\hline Airway clearance device & $11(20.8)$ & $6(7.3)$ & .031 & $6(16.7)$ & NA & NA \\
\hline Forced expiration + airway clearance device & $27(50.9)$ & $26(31.7)$ & .031 & $11(30.6)$ & $15(32.6)$ & .48 \\
\hline \multicolumn{7}{|l|}{ Type of airway clearance devices } \\
\hline Manual insufflator & NA & $1(3.1)$ & NA & $1(5.9)$ & NA & NA \\
\hline Pressure-cycled respirator & $19(52.8)$ & $13(40.6)$ & .32 & $11(64.7)$ & $2(13.3)$ & $<.01$ \\
\hline Insufflator/exsufflator & $16(44.4)$ & $19(59.4)$ & .48 & $12(70.6)$ & $7(46.7)$ & .43 \\
\hline Mechanical ventilation & $1(2.8)$ & $3(9.4)$ & .52 & NA & $3(20.0)$ & NA \\
\hline Intermittent positive-pressure breathing & NA & $3(9.4)$ & NA & $2(11.8)$ & $1(6.7)$ & .56 \\
\hline
\end{tabular}

$\overline{\text { Data are presented as }} n(\%) . N=192$ subjects; Intermittent NIV: $n=82$; Ventilator-Dependent: $n=110$; Continuous NIV: $n=47$; Invasive Ventilation: $n=63$. A Student $t$ test (equal variance) or Welche-Satterthwaite $t$ test (unequal variance) was used to analyze quantitative variables; a Mantel-Haenszel chi square test was used to analyze qualitative variables; a Fisher exact test was used when the sample sizes were small $(<5)$. NIV = noninvasive ventilation; $\mathrm{NA}=$ not applicable.

Table 4. Quality of Life Perception of Subjects With DMD

\begin{tabular}{|c|c|c|c|c|c|c|}
\hline Life Perception & Intermittent NIV & Ventilator-Dependent & $P$ & Continuous NIV & Invasive Ventilation & $P$ \\
\hline Medical care perception — satisfied & $68(86.1)$ & $92(83.6)$ & .92 & $43(91.5)$ & $49(77.8)$ & .34 \\
\hline \multicolumn{7}{|l|}{ Social life difficulty perception } \\
\hline Very difficult & $6(7.9)$ & $8(7.9)$ & .99 & $10(21.3)$ & $14(22.2)$ & .27 \\
\hline Rather difficult & $28(36.8)$ & $41(40.6)$ & & $33(7.2)$ & $35(55.6)$ & \\
\hline Low & $35(46.1)$ & $36(35.6)$ & & $4(8.5)$ & $10(15.9)$ & \\
\hline Very low & $7(9.2)$ & $16(15.8)$ & .73 & $4(6.3)$ & & \\
\hline \multicolumn{7}{|l|}{ Impact of disease and/or evolution } \\
\hline Professional activity — yes* & $21(28.4)$ & $34(33.7)$ & .38 & $14(31.8)$ & $20(35.1)$ & .31 \\
\hline Leisure and holidays — yes & $59(76.6)$ & $85(81.0)$ & .68 & $39(83.0)$ & $46(79.3)$ & .59 \\
\hline Family life — yes & $66(83.5)$ & $94(87.9)$ & .87 & $42(91.3)$ & $52(85.3)$ & .48 \\
\hline
\end{tabular}

Data are presented as $n(\%) . N=192$ subjects; Intermittent NIV: $n=82$; Ventilator-Dependent: $n=110$; Continuous NIV: $n=47$; Invasive Ventilation: $n=63$. A Student $t$ test (equal variance) or Welche-Satterthwaite $t$ test (unequal variance) was used to analyze quantitative variables; a Mantel-Haenszel chi square test was used to analyze qualitative variables; a Fisher exact test was used when the sample sizes were small $(<5)$. NIV $=$ noninvasive ventilation; $\mathrm{NA}=$ not applicable. $*$ Note that $57 \%$ of subjects were not employed and therefore experienced no impact in this area.

subpopulation. ${ }^{26}$ Cough assistance techniques may prevent respiratory failure due to inability to clear airway secretions and thus reduce the need for emergency intubation. ${ }^{27}$ These devices are generally proposed as early as possible to avoid the risks induced by ineffective cough. ${ }^{14}$ Tracheostomy should be considered when cough augmentation techniques are ineffective to avoid the risk of acute respiratory failure due to recurrent chest infections and respiratory insufficiency secondary to airway secretion stagnation. It is thus highly recommended that patients and their caregivers become familiar with cough assistance techniques during a period of clinical stability.

Ventilator-dependent subjects reported more swallowing difficulty and bloating than those with intermittent NIV. This was probably due to the progression of the disease, which affects upper airway and digestive muscles. ${ }^{28}$ This can cause food to penetrate the vestibule and accumulate as residue or cause aspiration, leading to lung infections. Moreover, swallowing difficulties in this population can be life-threatening. ${ }^{19}$ Solid food should be avoided, and the 


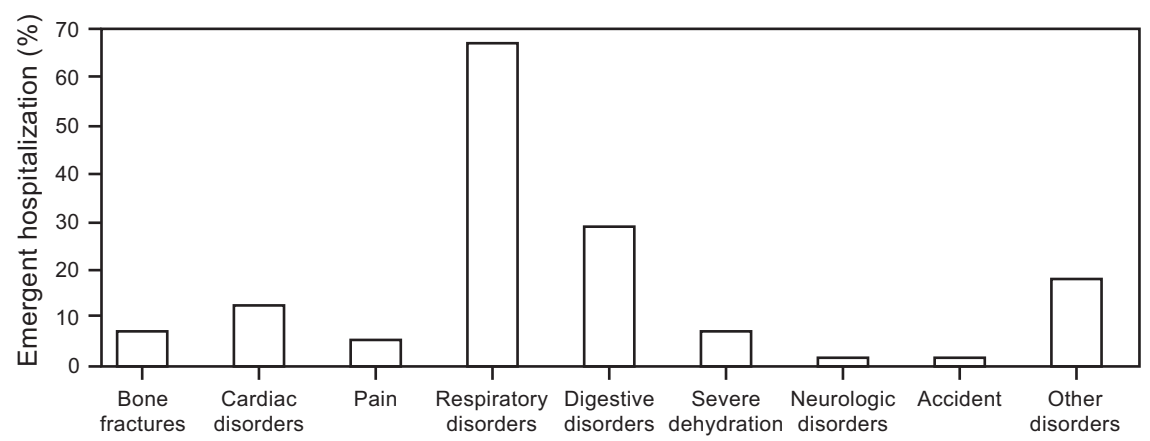

Fig. 2. Reasons for emergency hospitalization of ventilated subjects with Duchenne muscular dystrophy in the previous 2 y ( $n=55$ subjects).

intake of fluids encouraged. Interestingly, tracheostomy did not increase swallowing difficulties and seemed to improve the appetite of ventilator-dependent subjects. We previously reported that subjects who required mechanical ventilation during the day presented with breathing-swallowing asynchrony, which could contribute to the inhalation of food and dyspnea when swallowing; this improved after tracheostomy. ${ }^{29}$ We also observed that most of the subjects using daytime NIV discontinued mechanical ventilation while eating, making mealtimes long and difficult. ${ }^{30}$ Some subjects ate in 2 or 3 stages, resting and reconnecting the ventilator between stages. ${ }^{31}$ Ventilator disconnections during mealtimes were consistently associated with increases in transcutaneous carbon dioxide. ${ }^{30}$ It is therefore not surprising that these difficulties may reduce the appetite of subjects on continuous NIV. To avoid malnutrition, gastrostomy should therefore be considered for individuals on NIV, offering food by mouth only for pleasure.

Duchenne muscular dystrophy subjects who were ventilator-dependent, particularly those on invasive ventilation, reported more pain and poorer sleep quality, with more insomnia and daytime sleepiness. This can be explained by the fact that they have to be constantly repositioned at night to avoid pressure ulcers. ${ }^{32}$ The use of new pressure-relief mattresses has been reported to reduce tissue damage and hence improve subjects' quality of life, particularly those who are unable to move unaided. ${ }^{32,33}$ In this Duchenne muscular dystrophy population, we also observed a high level of anxiety, which could affect the quality of sleep, but this was not affected by continuous ventilation and tracheostomy.

In contrast to the study performed by Bach, ${ }^{22}$ we did not observe any significant link between the method of ventilation and speech difficulty. However, most of our subjects, particularly those who were tracheostomized, received voice management. Interestingly, new technology enables patients on invasive ventilation to speak during both inspiration and expiration. ${ }^{23,25,34}$ In addition, it has been clearly demonstrated that vocal intensity depends on subglottic pressure, and mechanical ventilation increases this pressure value above what is spontaneously possible..$^{25,34}$ Thus, mechanical ventilation can improve vocal intensity, whatever technique is used.

Communication is a major issue for tracheostomized individuals who are supported with mechanical ventilation, and it has a direct impact on their quality of life. ${ }^{23-25}$ Based on their specific aerodynamic characteristics, phonation valves can restore speech for these patients. ${ }^{34}$ In addition, subject-controlled PEEP enables good respiratory tolerance and significant speech improvement. ${ }^{23}$

$\mathrm{Bach}^{22}$ reported that individuals with neuromuscular disorders tended to prefer NIV techniques to tracheostomy. However, there is a lack of data supporting this finding in the Duchenne muscular dystrophy population, and the above-mentioned study included mainly individuals with sequelae of poliomyelitis and only 2 subjects with Duchenne muscular dystrophy. In polio survivors, studies suggest that quality of life is correlated with severity of impairment, antecedents, and health-promoting behaviors, ${ }^{35,36}$ which is not the case in Duchenne muscular dystrophy. ${ }^{9}$ Our results confirm this observation because all of the subjects in our study perceived similar difficulties with their social life, whatever the level of dependence and type of ventilation.

Most of our subjects were satisfied with their medical care, regardless of the level of dependence and type of mechanical ventilation. However, they reported that the progression of the disease had affected their professional life, leisure/holidays, and family life. A recent study reported that individuals with Duchenne muscular dystrophy had poor quality of life, related both to their physical condition and to social life. ${ }^{37} \mathrm{~A}$ valuable rehabilitation goal for subjects with Duchenne muscular dystrophy is to encourage participation in social activities. One way of improving quality of life could be to improve arm function with a functional arm exoskeleton. ${ }^{38,39}$ A happier and more hopeful life can be promoted by increasing social support and improving the knowledge of professionals and families. ${ }^{40}$

\section{Limitations of the Study}

The questionnaire we used provided information about how subjects with Duchenne muscular dystrophy perceive 


\section{Mechanical Ventilation in Duchenne Muscular Dystrophy}

their quality of life. However, its results cannot be generalized to all subjects with Duchenne muscular dystrophy because the questions are not standardized and therefore cannot be reproduced.

\section{Conclusions}

Continuous and invasive mechanical ventilation did not impact our Duchenne muscular dystrophy subjects' perception of their quality of life, apart from more insomnia, which can be explained by the fact that they need constant repositioning in bed. The use of different anti-pressure mattresses should be tested and compared to prevent pressure ulcers and thus improve the sleep of these individuals.

Management of speech difficulties is very important for these individuals and can improve their quality of life and social inclusion. This is an important factor to consider when subjects have to decide whether to have a tracheostomy due to problems with noninvasive mechanical ventilation. The feedback from ventilator-dependent individuals with Duchenne muscular dystrophy who have previously made this choice or experienced either invasive ventilation or NIV techniques could be useful for younger people with Duchenne muscular dystrophy.

\section{REFERENCES}

1. Emery AE. Population frequencies of inherited neuromuscular diseases-a world survey. Neuromuscul Disord 1991;1(1):19-29.

2. Moser H. Duchenne muscular dystrophy: pathogenetic aspects and genetic prevention. Hum Genet 1984;66(1):17-40.

3. Eagle M, Baudouin SV, Chandler C, Giddings DR, Bullock R, Bushby K. Survival in Duchenne muscular dystrophy: improvements in life expectancy since 1967 and the impact of home nocturnal ventilation. Neuromuscul Disord 2002;12(10):926-929.

4. American Thoracic Society/European Respiratory Society. ATS/ERS Statement on respiratory muscle testing. Am J Respir Crit Care Med 2002;166(4):518-624.

5. Weinberg J, Klefbeck B, Borg J, Svanborg E. Polysomnography in chronic neuromuscular disease. Respiration 2003;70(4):349-354.

6. Ogna A, Quera Salva MA, Prigent H, Mroue G, Vaugier I, Annane D, et al. Nocturnal hypoventilation in neuromuscular disease: prevalence according to different definitions issued from the literature. Sleep Breath 2016;20(2):575-581.

7. Bach JR, Campagnolo DI, Hoeman S. Life satisfaction of individuals with Duchenne muscular dystrophy using long-term mechanical ventilatory support. Am J Phys Med Rehabil 1991;70(3):129-135.

8. Simonds AK, Muntoni F, Heather S, Fielding S. Impact of nasal ventilation on survival in hypercapnic Duchenne muscular dystrophy. Thorax 1998;53(11):949-952.

9. Kohler M, Clarenbach CF, Böni L, Brack T, Russi EW, Bloch KE. Quality of life, physical disability, and respiratory impairment in Duchenne muscular dystrophy. Am J Respir Crit Care Med 2005; 172 (8):1032-1036.

10. Windisch W, Freidel K, Schucher B, Baumann H, Wiebel M, Matthys H, Petermann F. Evaluation of health-related quality of life using the MOS 36-Item Short-Form Health Status Survey in patients receiving noninvasive positive pressure ventilation. Intensive Care Med 2003;29 (4):615-621.
11. Mellies U, Ragette R, Dohna Schwake C, Boehm H, Voit T, Teschler $\mathrm{H}$. Long-term noninvasive ventilation in children and adolescents with neuromuscular disorders. Eur Respir J 2003;22(4):631-636.

12. Robert D, Léger P, Gaussorgues P, Gérard M. Mechanical ventilation at home by tracheotomy of patients with chronic respiratory insufficiency. Medical conditions of indications and practical modalities of equipment. Rev Prat 1987;37(17):1007-1014.

13. Toussaint M, Steens M, Wasteels G, Soudon P. Diurnal ventilation via mouthpiece: survival in end-stage Duchenne patients. Eur Respir J 2006;28(3):549-555.

14. Finder JD, Birnkrant D, Carl J, Farber HJ, Gozal D, Iannaccone ST, et al. Respiratory care of the patient with Duchenne muscular dystrophy: ATS consensus statement. Am J Respir Crit Care Med 2004;170 (4):456-465.

15. Bach JR, Alba AS, Saporito LR. Intermittent positive pressure ventilation via the mouth as an alternative to tracheostomy for 257 ventilator users. Chest 1993;103(1):174-182.

16. Birnkrant DJ, Bushby K, Bann CM, Alman BA, Apkon SD, Blackwell A, et al. Diagnosis and management of Duchenne muscular dystrophy, part 2: respiratory, cardiac, bone health, and orthopaedic management. Lancet Neurol 2018;17(4):347-361.

17. Windisch W, Brambring J, Budweiser S, Dellweg D, Geiseler J, Gerhard F, et al Nichtinvasive und invasive beatmung als therapie der chronischen respiratorischen insuffizienz. Pneumologie 2010;64 (4):207-240

18. McKim DA, Griller N, LeBlanc C, Woolnough A, King J. Twentyfour hour noninvasive ventilation in Duchenne muscular dystrophy: a safe alternative to tracheostomy. Can Respir J 2013;20(1):e5-e9.

19. Boussaïd G, Lofaso F, Santos DB, Vaugier I, Pottier S, Prigent H, et al. Impact of invasive ventilation on survival when non-invasive ventilation is ineffective in patients with Duchenne muscular dystrophy: a prospective cohort. Respir Med 2016;115:26-32.

20. Hess DR. The growing role of noninvasive ventilation in patients requiring prolonged mechanical ventilation. Respir Care 2012;57 (6):900-918.

21. Villanova M, Brancalion B, Mehta AD. Duchenne muscular dystrophy: life prolongation by noninvasive ventilatory support. Am J Phys Med Rehabil 2014;93(7):595-599.

22. Bach JR. A comparison of long-term ventilatory support alternatives from the perspective of the patient and care giver. Chest 1993;104 (6):1702-1706.

23. Garguilo M, Leroux K, Lejaille M, Pascal S, Orlikowski D, Lofaso F, Prigent H. Patient-controlled positive end-expiratory pressure with neuromuscular disease: effect on speech in patients with tracheostomy and mechanical ventilation support. Chest 2013;143(5):1243-1251.

24. Terzi N, Orlikowski D, Aegerter P, Lejaille M, Ruquet M, Zalcman G, et al. Breathing-swallowing interaction in neuromuscular patients: a physiological evaluation. Am J Respir Crit Care Med 2007;175 (3):269-276.

25. Terzi N, Prigent H, Lejaille M, Falaize L, Annane D, Orlikowski D, Lofaso F. Impact of tracheostomy on swallowing performance in Duchenne muscular dystrophy. Neuromuscul Disord 2010;20(8):493498.

26. Benditt JO, Boitano LJ. Pulmonary issues in patients with chronic neuromuscular disease. Am J Respir Crit Care Med 2013;187(10):10461055 .

27. Mier-Jedrzejowicz A, Brophy C, Moxham J, Green M. Assessment of diaphragm weakness. Am Rev Respir Dis 1988;137(4):877-883.

28. Khirani S, Ramirez A, Aubertin G, Boulé M, Chemouny C, Forin V, Fauroux B. Respiratory muscle decline in Duchenne muscular dystrophy. Pediatr Pulmonol 2014;49(5):473-481.

29. Terzi N, Normand H, Dumanowski E, Ramakers M, Seguin A, Daubin $\mathrm{C}$, et al. Noninvasive ventilation and breathing-swallowing interplay 


\section{Mechanical Ventilation in Duchenne Muscular Dystrophy}

in chronic obstructive pulmonary disease. Crit Care Med 2014;42 (3):565-573

30. Nardi J, Leroux K, Orlikowski D, Prigent H, Lofaso F. Home monitoring of daytime mouthpiece ventilation effectiveness in patients with neuromuscular disease. Chron Respir Dis 2016;13(1):67-74.

31. Koreska J, Albisser AM. A new foam for support of the physically handicapped. Biomed Eng 1975;10(2):56-62.

32. Chamanga E, Butcher A. An evaluation of a novel alternating mattress and cushion technology. Br J Community Nurs 2016;21(Suppl 3):S25S31.

33. Newton H. Evaluating a pressure-redistribution mattress replacement system. Br J Nurs 2014;23(Suppl 20):S30-S35.

34. Prigent H, Orlikowski D, Blumen MB, Leroux K, Legrand L, Lejaille $\mathrm{M}$, et al. Characteristics of tracheostomy phonation valves. Eur Respir J 2006;27(5):992-996.

35. Tate D, Kirsch N, Maynard F, Peterson C, Forchheimer M, Roller A, Hansen N. Coping with the late effects: differences between depressed and nondepressed polio survivors. Am J Phys Med Rehabil 1994;73 (1):27-35

36. Stuifbergen AK, Seraphine A, Harrison T, Adachi E. An explanatory model of health promotion and quality of life for persons with postpolio syndrome. Soc Sci Med 2005;60(2):383-393.

37. Lue YJ, Chen SS, Lu YM. Quality of life of patients with Duchenne muscular dystrophy: from adolescence to young men. Disabil Rehabil 2016:1-6.

38. Rahman T, Sample W, Seliktar R, Scavina MT, Clark AL, Moran K, Alexander MA. Design and testing of a functional arm orthosis in patients with neuromuscular diseases. IEEE Trans Neural Syst Rehabil Eng 2007;15(2):244-251.

39. Gunn M, Shank TM, Eppes M, Hossain J, Rahman T. User evaluation of a dynamic arm orthosis for people with neuromuscular disorders. IEEE Trans Neural Syst Rehabil Eng 2016;24(12):1277-1283.

40. Zamani G, Heidari M, Azizi Malamiri R, Ashrafi MR, Mohammadi M, Shervin Badv R, et al. The quality of life in boys with Duchenne muscular dystrophy. Neuromuscul Disord 2016;26(7):423-427. 